\begin{tabular}{|c|l|}
\hline Title & $\begin{array}{l}\text { Purification and characterisation of blarinasin, a new tissue kall likrein-like protease from the short-tailed shrew Blarina } \\
\text { brevicauda: comparative studies with blarina toxin }\end{array}$ \\
\hline Author(s) & $\begin{array}{l}\text { Kita, Masaki; Okumura, Y uushi; Ohdachi, Satoshi D.; Oba, Y uichi; Y oshikuni, Michiyasu; Nakamura, Y asuo; Kido, } \\
\text { Hiroshi; Uemura, Daisuke }\end{array}$ \\
\hline Citation & $\begin{array}{l}\text { Biological Chemistry, 386(2), 177-182 } \\
\text { https://doi.org/L0.1515/BC.2005.022 }\end{array}$ \\
\hline Issue Date & 2005-02 \\
\hline Doc URL & http://hdl.handle.net/2115/7398 \\
\hline Type & article(author version) \\
\hline File Information & BC386_2.pdf \\
\hline
\end{tabular}

Instructions for use 


\title{
Purification and characterisation of blarinasin, a new tissue kallikrein-like protease from the short-tailed shrew Blarina brevicauda - comparative studies with blarina toxin
}

\begin{abstract}
Masaki Kita ${ }^{1}$, Yuushi Okumura ${ }^{2}$, Satoshi D. Ohdachi ${ }^{3}$, Yuichi Oba ${ }^{4}$, Michiyasu
\end{abstract} Yoshikuni $^{5}$, Yasuo Nakamura ${ }^{2, a}$, Hiroshi Kido ${ }^{2}$, and Daisuke Uemura,

${ }^{1}$ Research Center for Materials Science, ${ }^{4}$ Graduate School of Bioagricultural Sciences, and ${ }^{6}$ Graduate School of Science, Nagoya University, Furo-cho, Chikusa, Nagoya 464-8602, Japan

${ }^{2}$ Institute for Enzyme Research, The University of Tokushima, Kuramoto-Cho 3-18-15, Tokushima 770-8503, Japan

${ }^{3}$ Institute of Low Temperature Science, Hokkaido University, Kita-19 Nishi-8, Kita-ku, Sapporo 060-0819, Japan

${ }^{5}$ Laboratory of Reproductive Biology, National Institute for Basic Biology, Nishigonaka 38, Myodaiji, Okazaki 444-8585, Japan

* Corresponding author

Daisuke Uemura, Ph. D. Address: Furo-cho, Chikusa, Nagoya 464-8602, Japan. Phone/FAX: +81-52-789-3654. E-mail: uemura@chem3.chem.nagoya-u.ac.jp.

a Current address: Department of Parasitology, Kurume University, Asahi-machi 67, Kurume 830-0011, Japan.

Running Title : Kallikrein-like Protease from the Short-tailed Shrew 
Abstract

A new tissue kallikrein-like protease, blarinasin, has been purified from the salivary glands of the short-tailed shrew Blarina brevicauda. Blarinasin is a 32-kDa N-glycosylated protease with isoelectric values ranging between 5.3 and 5.7, and an optimum pH of 8.5 for enzyme activity. The cloned blarinasin cDNA coded for a pre-pro-sequence and a mature peptide of 252 amino acids with a typical catalytic triad for serine proteases and $43.7-54.0 \%$ identity to other mammalian tissue kallikreins. Blarinasin preferentially hydrolyzed Pro-Phe-Arg-4-methylcoumaryl-7-amide (MCA) and N-tert-butyloxycarbonyl-Val-Leu-Lys-MCA, and preferentially converted human high molecular weight kininogen (HK) to bradykinin. The activity of blarinasin was prominently inhibited by aprotinin $\left(K_{\mathrm{i}}=3.4 \mathrm{~nm}\right)$. Similar kallikrein-like protease, a lethal venom blarina toxin, has previously been purified from the salivary glands of the shrew Blarina and shows $67.9 \%$ identity to blarinasin. However, blarinasin was no toxic in mice. Blarinasin was a most abundant kallikrein-like protease and represented $70-75 \%$ of kallikrein-like enzymes in the salivary gland of $B$. brevicauda.

Key words: Amino acid sequence analysis; Blarinasin; Blarina toxin; Salivary glands; Short-tailed shrew; Tissue kallikrein 
The American short-tailed shrew Blarina brevicauda (Say, 1923) is one of the few venomous mammals in the world (Dufton, 1992). This shrew produces a potent salivary venom that may cause paralysis and death due to respiratory failure and circulatory malfunctions in mouse-sized animals (Pucek, 1968; Pearson, 1942). B. brevicauda eats insects and also vertebrates, including some larger than themselves, such as murid rodents and frogs (Churchfield, 1990; Babcock, 1914). Hence, this shrew may use venom to catch its prey.

According to the fossil record, the Insectivora may one of the longest established mammalian orders and probably that from which other placental orders are ultimately descended (Crompton et al., 1978; Crompton and Jenkins, 1979). Thus, enzymes produced by insectivores are expected to be more primitive than their counterparts in higher mammals, and may provide important information concerning enzyme structure and function in the mammals. Few serine proteases from the Insectivora have been identified. A $30 \mathrm{kDa}$ tissue kallikrein from the salivary gland of the Eastern Atlantic mole Scalopus aquaticus has been partially purifed (Richards et al., 1996), and several serine proteases, such as factor $\mathrm{X}$ and neutrophil elastase, have been cloned from a spleen cDNA library of the platypus Ornithorhynchus anatinus (Poorafshar et al., 2000).

Due to the interesting ecology of shrews, we have sought to isolate biologically active substances from the shrew $B$. brevicauda. Recently, we have purified and characterised the blarina toxin (BLTX), a lethal mammalian venom from the submaxillary and sublingual glands (Kita et al., 2004). It consists of a mature peptide of 253 amino acids with a high degree of identity with tissue kallikrein. Mice administered BLTX developed irregular respiration, paralysis and convulsions before dying. BLTX converts kininogens to kinins and caused vasodilation, though the mechanisms underlying its 
lethal toxicity have not been characterised. On the course of BLTX purification, we found a new kallikrein-like protease named blarinasin from $B$. brevicauda salivary glands. We report here the purification, characterisation and molecular cloning of blarinasin and discuss its structure and enzymatic properties compared to those of BLTX.

Blarinasin was purified from extracts of the shrew B. brevicauda submaxillary and sublingual glands (salivary glands) through a series of standard chromatographic procedures. BLTX fraction identified by toxicity was completely separated from blarinasin by a Mono-Q anion exchange column chromatography on the course of purification (Kita et al., 2004). Enzymatic activity was assessed by measuring the proteolysis of Pro-Phe-Arg-4-methyl-coumaryl-7-amide (MCA). Proteolytic activity coincided with a protein peak on analytical gel permeation, anion-exchange, and hydrophobic high performance liquid chromatography. Starting from $17.1 \mathrm{mg}$ of shrew salivary glands, $32.3 \mu \mathrm{g}$ of purified blarinasin was obtained with a total recovery of $4.7 \%$ and a 5.58-fold purification from the crude extract. Blarinasin was unstable and lost its activity under gel permeation chromatography at room temperature as well as by freezing and thawing. Purified blarinasin yielded a single protein band with a molecular mass of approximately $32 \mathrm{kDa}$ under reducing conditions on SDS/PAGE (Figure 1A). A comparison of the 2D-PAGE pattern of the crude B. brevicauda salivary gland extract with a purified blarinasin revealed that blarinasin migrated as 8 major spots with similar molecular sizes and different isoelectric points between 5.3 and 5.7 (arrows 4 to 11, Figure 1B). BLTX migrated as 3 spots (arrows 1 to 3 ) with higher isoelectric points than most of the blarinasin spots on 2D-PAGE. Based on the specific activity of blarinasin and the 2D-PAGE pattern of extracted salivary glands, blarinasin was estimated to be $70 \%$ to $75 \%$ of the total kallikrein activity found in salivary glands. By comparison, BLTX 
(Kita et al., 2004) accounts for approximately 5-fold less activity than blarinasin. Blarinasin, up to $20 \mathrm{mg} \cdot \mathrm{kg}^{-1}$, i.p., was not toxic in mice, whereas the $\mathrm{LD}_{50}$ of BLTX was approximately $1 \mathrm{mg} \cdot \mathrm{kg}^{-1}$ (data not shown).

Blarinasin cDNA was cloned from $B$. brevicauda submaxillary and sublingual glands by PCR using degenerate oligonucleotides designed from the sequences of the $\mathrm{N}$-terminus, tryptic peptide fragments, and the consensus sequences of active sites of serine proteases. The isolated cDNA consisted of $962 \mathrm{bp}$ and contained a single putative open reading frame of 843 bp with a proposed initiation codon of ATG at nt 42 and a 3'-untranslated region of $78 \mathrm{bp}$ with a polyadenylation signal (AATAAA) and a poly $(\mathrm{A})$ tail. The deduced amino acid sequence of blarinasin, the $\mathrm{N}$-terminal 15 residues of amino acid sequence starting from an I-V-G-G serine protease motif and the sequences of 7 trypsin cleavage fragments (K1-K7), are shown in Figure 2. Blarinasin was composed of 281 amino acids with a pre-pro-sequence and an active mature protein composed of 252 amino acids. The predicted molecular mass of blarinasin was $28.0 \mathrm{kDa}$. Due to the presence of one predicted N-glycosylation site $\left(\mathrm{Asn}^{122}\right)$, purified blarinasin was treated with $\mathrm{N}$ - and/or O-glycosidase under denaturing conditions. After treatment with $\mathrm{N}$-glycosidase, the $32 \mathrm{kDa}$ blarinasin protein band shifted to a single 27-28 kDa band on SDS/PAGE, being consistent with the molecular mass of the mature polypeptide backbone of blarinasin calculated (data not shown).

The optimum $\mathrm{pH}$ for blarinasin enzyme activity was 8.5 , identical to that reported for tissue kallikreins (Mason et al., 1983; Fukushima et al., 1985), and nearly equal to that of BLTX (Kita et al., 2004). Table 1 shows the substrate specificities of blarinasin and BLTX. Blarinasin preferentially hydrolysed substrates with an Arg or Lys at the P1 position and a hydrophobic amino acid at the P2 position. Of the substrates tested, 
Boc-Val-Leu-Lys-MCA was the best substrate with specific activity of $6.82 \mathrm{U} / \mathrm{mg}$ protein. Boc-Glu-Lys-Lys-MCA, Boc-Glu(OBzl)-Ala-Arg-MCA, Boc-Val-Pro-Arg-MCA, Z-Phe-Arg-MCA and Pro-Phe-Arg-MCA, which are synthetic substrates for plasmin, factor Xla, $\alpha$-thrombin, plasma kallikrein, and tissue kallikrein, respectively, were the second best substrates, although the activities with these substrates were $3 \%$ to $5 \%$ of that with Boc-Val-Leu-Lys-MCA. Substrates with hydrophobic amino acids, such as Tyr, Phe, Ala, and Pro, at P1 position were also hydrolysed, but at only $0.1 \%$ to $1 \%$ that with Boc-Val-Leu-Lys-MCA. On the other hand, BLTX showed a narrow substrate specificity and both Pro-Phe-Arg-MCA and Boc-Val-Leu-Lys-MCA were the best substrates with specific activities of 267.4 and $244.1 \mathrm{mU} / \mathrm{mg}$ protein, respectively.

The activity of blarinasin was markedly inhibited by aprotinin at the concentration of $0.1 \mu \mathrm{M}\left(K_{\mathrm{i}}=3.4 \times 10^{-9} \mathrm{M}\right)$, moderately inhibited by secretory leukoprotease inhibitor $\left(\right.$ SLPI, $\left.K_{\mathrm{i}}=8.7 \times 10^{-8} \mathrm{M}\right)$, leupeptin, benzamidine, phenylmethanesulfonyl fluoride (PMSF) at the concentration of $1 \mu \mathrm{M}$, and not inhibited by EDTA or $\alpha_{1}$-protease inhibitor $\left(\alpha_{1} \mathrm{PI}\right)$ (Table 2). The inhibitor spectrum of blarinasin shows the significant similarity with that of BLTX.

Blarinasin converted human high molecular weight kininogen (HK) into a major 58-63 $\mathrm{kDa}$ protein fragment and various smaller peptides in a time-dependent manner on SDS/PAGE analysis (data not shown). The major peptide generated after HK hydrolysis by blarinasin was bradykinin (BK) (Figure 3), being similar to those generated by BLTX and porcine pancreas kallikrein (PPK).

Amino acid sequence of mature blarinasin bore the highest identity of $67.9 \%$ with BLTX, and identities of $54.0,54.0,53.6,54.0,44.0,43.7,32.9$, and $30.0 \%$ with, 
respectively, monkey glandular kallikrein from the crab-eating macaque Macaca fascicularis (Lin et al., 1993), dog pancreas kallikrein from Canis familiaris (Gauthier et al., 1994), human tissue kallikrein 1 (hK1) (Fukushima et al., 1985), human prostate specific antigen (PSA) (Watt et al., 1986), mouse tissue kallikrein 1 (mGK1) (Mason et al., 1983), rat urinary kallikrein 1 (RUK1) (Swift et al., 1982), human plasmin (Malinowski et al., 1984), and human plasma kallikrein (huPK) (Chung et al., 1986) (Figure 4). Blarinasin has highly conserved residues flanking the residues of the catalytic triad $\left(\mathrm{His}^{72}, \mathrm{Asp}^{138}\right.$, and $\left.\mathrm{Ser}^{233}\right)$, and 10 highly conserved cysteine residues that may form disulfide bonds and stabilise the catalytic pocket. It has a characteristic motif (residues 114-132) containing a unique insertion of 10 residues, $D^{123}$ TYYDEISLG ${ }^{132}$. BLTX has a non-homologous insertion of 10 residues, $\mathrm{L}^{123}$ TFFYKTFLG ${ }^{132}$, in the same position. To our knowledge, these characteristic insertions near the position of the presumed catalytic triad $\left(\mathrm{Asp}^{138}\right)$ are rare, and have been shown only in the sequences of gila toxin (GTX) and horridum toxin, venoms from the Mexican lizard Heloderma horridum (Utaisincharoen et al., 1993). The pre-pro-sequence of blarinasin also showed high similarity to those of mammalian tissue kallikreins listed in Figure 4 except for a unique insertion of 6 residues, $\mathrm{P}^{20} \mathrm{GPSIE}^{25}$.

Blarinasin hydrolysed Boc-Val-Leu-Lys-MCA most rapidly, and its specific activity with this substrate was 27.9 -fold higher than that of BLTX. On the other hand, BLTX preferentially hydrolysed Pro-Phe-Arg-MCA and the specific activity of BLTX was 1.37-fold higher than that of blarinasin. The former substrate for blarinasin and its analogues, such as D- and/or DL-Val-Leu-Lys-pNA, are known as general substrates for plasmin. The substrate specificity of blarinasin is similar to those of hK1 (Fujimoto et al., 1990), PPK (Blaber et al., 1989), and RUK1 (Bedi, 1982). These observations suggest 
that a lysine at the P1 site is favoured for blarinasin. As with BLTX, aprotinin and SLPI efficiently inhibited the activity of blarinasin. In contrast, UTI, benzamidine, and PMSF moderately inhibited the activity of blarinasin at concentrations of $1 \mu \mathrm{M}$, but these inhibitors inhibited the activity of BLTX a little (Kita et al., 2004). Despite the similarities between the amino acid sequences and the enzymatic properties of blarinasin and BLTX, blarinasin did not show any toxicity against mice, as observed with other mammalian tissue kallikreins.

In general, tissue kallikreins are acidic $\mathrm{N}$ - and $\mathrm{O}$ - glycoproteins with molecular heterogeneity. Both blarinasin and BLTX showed micro-heterogeneous by $\mathrm{N}$-glycosylation. Analysis of blarinasin and BLTX by SDS/PAGE revealed different molecular size bands ( 32 and $35 \mathrm{kDa}$ ), though, after deglycosylation, these bands were shifted to a single band with a molecular size of $27-28 \mathrm{kDa}$. Based on the typical $\mathrm{N}$-glycosylation motif (Asn-Xaa-Ser/Thr), blarinasin has a putative $\mathrm{N}$-glycosylation site at $\mathrm{Asn}^{122}$ (Figure 2), while BLTX possesses two. The difference in the glycosylation may play a role in the different toxicity and enzymatic properties of blarinasin and BLTX.

Among lizard venoms, GTX and horridum toxin are classified as kallikrein analogues because of their amino acid sequences and protease activities (Utaisincharoen et al., 1993; Hendon and Tu, 1981; Datta and Tu, 1997). The LD $_{50}$ values of GTX and horridum toxin injected are $2.5 \mathrm{mg} \cdot \mathrm{kg}^{-1}$ body weight, i.v., but lethality may be synergistically increased approximately 8 -fold when combined. In contrast, the toxicity of BLTX was not influenced by blarinasin. Although the in vivo substrates of these two kallikrein-like proteases have not been clarified, blarinasin may be a typical tissue kallikrein-like protease secreted in the B. brevicauda salivary glands, similar to other mammalian tissue kallikreins. On the other hand, BLTX cleaves substrates that result in 
products that cause paralysis and respiratory failure.

\section{Acknowledgements}

This research was supported in part by Grants-in-Aids for Scientific Research on Priority Area (A) and for Creative Scientific Research from the Ministry of Education, Culture, Sports, Science, and Technology, Japan (to D. U.). The Blarina shrew project was conducted on property owned by the University of Michigan and in collaboration

with Dr. P. Myers. We thank Dr. K. Suenaga and Dr. S. Kawada (Nagoya University), A. P. G. Dowling (University of Michigan), A. Uesugi and F. Okabe (Hokkaido University) for collecting Blarina specimens.

\section{$\underline{\text { References }}$}

Babcock, H.L. (1914). Some observations on the food habits of the short-tailed shrew (Blarina Brevicauda). Science 40, 526-530.

Bedi, G.S. (1992). Purification of rat urinary kallikrein - comparative studies with rat submadibular gland and kallikrein like serine protease. Prep. Biochem. 22, 239-256.

Blaber, M., Isackson, P.J., Marsters, J.C., Burnier, J.P., and Bradshrw, R.A. (1989). Substrate specificities of growth-factor associated kallikreins of the mouse submadibular gland. Biochemistry 28, 7813-7819.

Chung, D.W., Fujikawa, K., McMullen, B.A., and Davie, E.W. (1986). Human plasma prekallikrein, a zymogen to a serine protease that contains 4 tandem repeats. Biochemistry 25, 2410-2417.

Churchfield, S. (1990). The Natural History of Shrews (A\&C Black, London). 
Crompton, A.W., Taylor, R., and Jagger, J.A. (1978). Evolution of homeothermy in mammals. Nature 272, 333-336.

Crompton, A.W., and Jenkins, F.A. (1979). Mesozoic mammals. Lillegraven, J.A., Kielan-Jaworowska, Z., and Clemens., W.A., eds. (University of Callifornia Press, Berkley). pp. 59-73.

Datta, G., and Tu, A.T. (1997). Structure and other chemical characterizations of gila toxin, a lethal toxin from lizard venom. J. Peptide Res. 50, 443-450.

Dufton, M.J. (1992). Venomous mammals. Pharmacol. Ther. 53, 199-215.

Fujimoto, Y., Suzuki, C., Watanabe, Y., Matsuda, Y., and Akihama, S. (1990). Purification and characterization of a kallikrein from human submaxillary glands. Biochem. Med. Metab. Biol. 44, 218-227.

Fukushima, D., Kitamura, N. and Nakanishi, S. (1985). Nucleotide sequence of cloned cDNA for human pancreatic kallikrein. Biochemistry 24, 8037-8043.

Gauthier, E.R., Dumas, C., Chapdelaine, P., Tremblay, R.R. and Dube, J.Y., (1994). Characterization of Canine pancreas kallikrein cDNA. Biochim. Biophys. Acta 1218, 102-104.

Hendon, R.A., and Tu, A.T. (1981). Biochemical-characterization of the lizard toxin gilatoxin. Biochemistry 20,3517-3522.

Kido, H., Yokogishi, Y., Sakai, K., Tashio, M., Kishino, Y., Fukutomi, A., and Katunuma, N. (1992). Isolation and characterization of a novel trypsin-like protease found in rat bronchiolar epithelial Clara cells. J. Biol. Chem. 267, 13573-13579.

Kita, M., Nakamura, Y., Okumura, Y., Ohdachi, S.D., Oba, Y., Yoshikuni, M., Kido, H., and Uemura, D. (2004). Blarina toxin, a mammalian lethal venom from the short-tailed shrew Blarina brevicauda: isolation and characterization. Proc. Natl. 
Acad. Sci. USA 101, 7542-7547.

Lin, F.K., Lin, C.H., Chou, C.C., Chen, K., Lu, H.S., Bacheller, W., Herrera, C., Jones, T., Chao, J. and Chao, L. (1993). Molecular cloning and sequence analysis of the monkey and human tissue kallikrein genes. Biochim. Biophys. Acta 1173, 325-328.

Malinowski, D.P., Sadler, J.E., and Davie, E.W. (1984). Characterization of a complementary deoxyribonucleic-acid coding for human and bovine plasminogen. Biochemistry 23, 4243-4250.

Mason, A.J., Evans, B.A., Cox, D.R., Shine, J. and Richards, R.I. (1983). Structure of mouse kallikrein gene family suggests a role in specific processing of biologically active peptides. Nature $303,300-307$.

Pearson, O. P. (1942). On the cause and nature of a poisonous action provided by the bite of shrew (Blarina brevicauda). J. Mamm. 23, 159-166.

Poorafshar, M., Aveskogh, M., Munday, B., and Hellman, L. (2000). Identification and structural analysis of four serine proteases in a monotreme, the platypus, Ornithorhynchus anatinus. Immunogenetics 52, 19-28.

Pucek, M. (1968). Venomous vertebrates. In: venomous animals and their venoms, Vol. 1. B'cherl, W., Buckley, E. A., and Deulofen, V., eds. (Academic Press, New York), pp. 43-50.

Richards, G. P., Zintz, C., and Chao, J. (1996). Purification and characterization of salivary kallikrein from an insectivore (Scalopus aquaticus): Substrate. Archives of Biochemistry and Biophysics 329, 104-112.

Swift, G.H., Dagorn, J.C., Ashley, P.L., Cummings, S.W. and MacDonald, R.J. (1982). Rat pancreatic kallikrein messenger-RNA nucleotide sequence and amino acid 
sequence of the encoded preproenzyme. Proc. Natl. Acad. Sci. USA 79, 7263-7267.

Utaisincharoen, P., Mackessy, S.P., Miller, R.A., and Tu, A.T. (1993). Complete primary structure and biochemical-properties of gilatoxin, a serine-protease with kallikrein-like and angiotensin-degrading activities. J. Biol. Chem. 268, 21975-21983.

Watt, K.W., Lee, P.J., M'Timculu, T., Chan, W.P., and Loor, R. (1986). Human prostate specific antigen structural and functional similarity with serine proteases. Proc. Natl. Acad. Sci. USA 83, 3166-3170. 
Table 1 Comparison of the Substrate Specificities of Blarinasin and Blarina Toxin.

\begin{tabular}{lcc}
\hline & \multicolumn{2}{c}{ Relative activity (\%) } \\
\cline { 2 - 3 } Substrate & Blarinasin & BLTX \\
\hline Pro-Phe-Arg-MCA & 100 & 100 \\
Arg-MCA & 8.6 & 0.0 \\
Boc-Ala-Gly-Pro-Arg-MCA & 9.0 & 19.4 \\
Boc-Gln-Ala-Arg-MCA & 30.6 & 7.8 \\
Boc-Gln-Arg-Arg-MCA & 3.5 & 0.0 \\
Boc-Gln-Gly-Arg-MCA & 10.0 & 0.0 \\
Boc-Glu-Lys-Lys-MCA & 153.2 & 18.0 \\
Boc-Glu(OBzl)-Ala-Arg-MCA & 162.0 & 35.0 \\
Boc-Glu(OBzI)-Gly-Arg-MCA & 172.5 & 5.3 \\
Boc-Gly-Arg-Arg-MCA & 26.6 & 0.0 \\
Boc-Leu-Lys-Arg-MCA & 0.0 & 10.7 \\
Boc-Leu-Shr-Thr-Arg-MCA & 4.0 & 0.0 \\
Boc-Leu-Thr-Arg-MCA & 39.5 & 2.2 \\
Boc-Phe-Ser-Arg-MCA & 55.6 & 8.1 \\
Boc-Val-Leu-Lys-MCA & 3482.2 & 91.3 \\
Boc-Val-Pro-Arg-MCA & 167.7 & 49.5 \\
Bz-Arg-MCA & 12.1 & 0.0 \\
Glt-Gly-Arg-MCA & 1.2 & 0.0 \\
Suc-Ala-Ala-Pro-Phe-MCA & 13.1 & 0.0 \\
Suc-Leu-Leu-Val-Tyr-MCA & 4.4 & 0.0 \\
Z-Phe-Arg-MCA & 119.3 & 0.0 \\
Suc-Ala-Pro-Ala-MCA & 33.9 & 0.0 \\
Suc-Gly-Pro-MCA & 28.2 & 0.0 \\
Boc-Gly-Lys-Arg-MCA & 0.0 & 0.0 \\
Boc-Ile-Glu-Gly-Arg-MCA & 0.0 & 0.0 \\
Boc-Leu-Arg-Arg-MCA & 0.0 & 0.0 \\
Z-Arg-Arg-MCA & & 0.0 \\
\hline
\end{tabular}

Enzyme activity using peptidyl-MCA substrates was analysed as previously described (Kido et al., 1992). Reactions were initiated by adding enzyme samples to $0.1 \mathrm{~mm}$ substrate in $50 \mathrm{~mm}$ Tris/ $\mathrm{HCl}$ buffer, $\mathrm{pH} 8.5$, in a total volume of $0.5 \mathrm{ml}$. Relative activities are expressed as percentages of the activity toward Pro-Phe-Arg-MCA (blarinasin, $7.02 \mathrm{mU} / \mathrm{ml}$; BLTX, $5.68 \mathrm{mU} / \mathrm{ml}$ ). Boc = $t$-butoxycarbonyl; $\mathrm{Z}=$ benzyloxycarbonyl; $\mathrm{Bz}=$ benzoyl; Suc $=$ succinyl . 
Table 2 Comparison of the Inhibitory Effects of Protease Inhibitors and EDTA on the Proteolytic Activity of Blarinasin and Blarina Toxin.

\begin{tabular}{lccc}
\hline Inhibitor & $\begin{array}{c}\text { Concentration } \\
(\mu \mathrm{M})\end{array}$ & \multicolumn{2}{c}{ Residual activity $(\%)$} \\
\cline { 3 - 4 } & - & Blarinasin $^{a}$ & BLTX $^{b}$ \\
\hline None & 0.1 & 100 & 100 \\
Aprotinin & 1 & 44 & 22 \\
Leupeptin & 1 & 88 & 65 \\
KSTI & 1 & 96 & 67 \\
$\alpha_{1}$-Protease inhibitor & 1 & 80 & 113 \\
UTI & 1 & 26 & 108 \\
SLPI & 1 & 48 & 50 \\
Benzamidine & 1 & 40 & 78 \\
PMSF & 10,000 & 94 & 85 \\
EDTA & & & 99 \\
\hline
\end{tabular}

Blarinasin and BLTX were pre-incubated with various inhibitors for 5 min at $37{ }^{\circ} \mathrm{C}$ and enzyme reaction was started by addition of substrate in $50 \mathrm{~mm}$ Tris/HCl buffer, $\mathrm{pH}$ 8.5. Residual activity was calculated as a percentage of that of the enzyme without inhibitor. KSTI = Kunitz-type soybean trypsin inhibitor; SLPI = secretory leukoprotease inhibitor; $\mathrm{PMSF}=$ phenylmethanesulfonyl fluoride; UTI = urinary trypsin inhibitor.

${ }^{a}$ Substrate, Boc-Val-Leu-Lys-MCA.

${ }^{b}$ Substrate, Pro-Phe-Arg-MCA. 


\section{Fiqures}

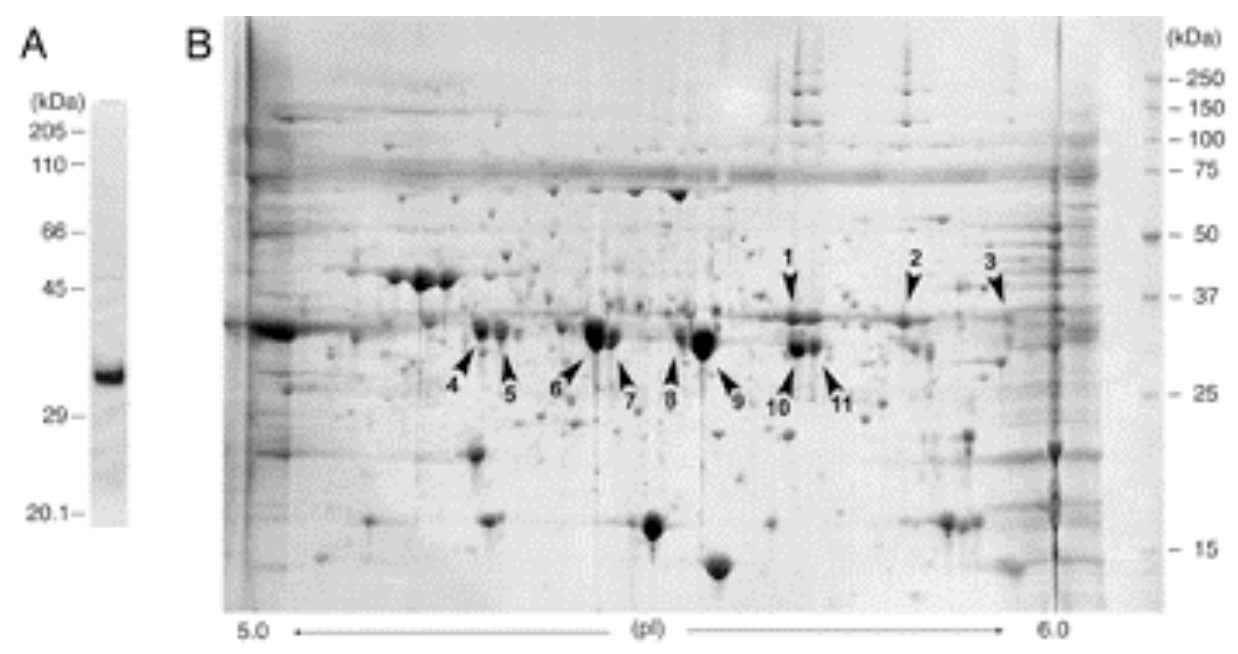

Figure 1 SDS/PAGE Analysis of Purified Blarinasin (A) and 2D-PAGE Analysis of the Extracts of Blarina Salivary Glands (B).

(A) SDS/PAGE analysis of blarinasin under reducing conditions. Purified blarinasin (180 ng) was run on $12.5 \%$ polyacrylamide gel, and protein bands are shown by silver staining. (B) Analysis of the extracts of Blarina salivary glands by 2D-PAGE. Cysteine residues were carbamidomethylated with iodoacetamide. The protein bands were stained with SYPRO Ruby and analysed at excitation and emission wavelengths of 532 $\mathrm{nm}$ and $610 \mathrm{~nm}$, respectively. Arrows 1 to 3 , and 4 to 11 indicate the spots of BLTX and blarinasin, respectively. 


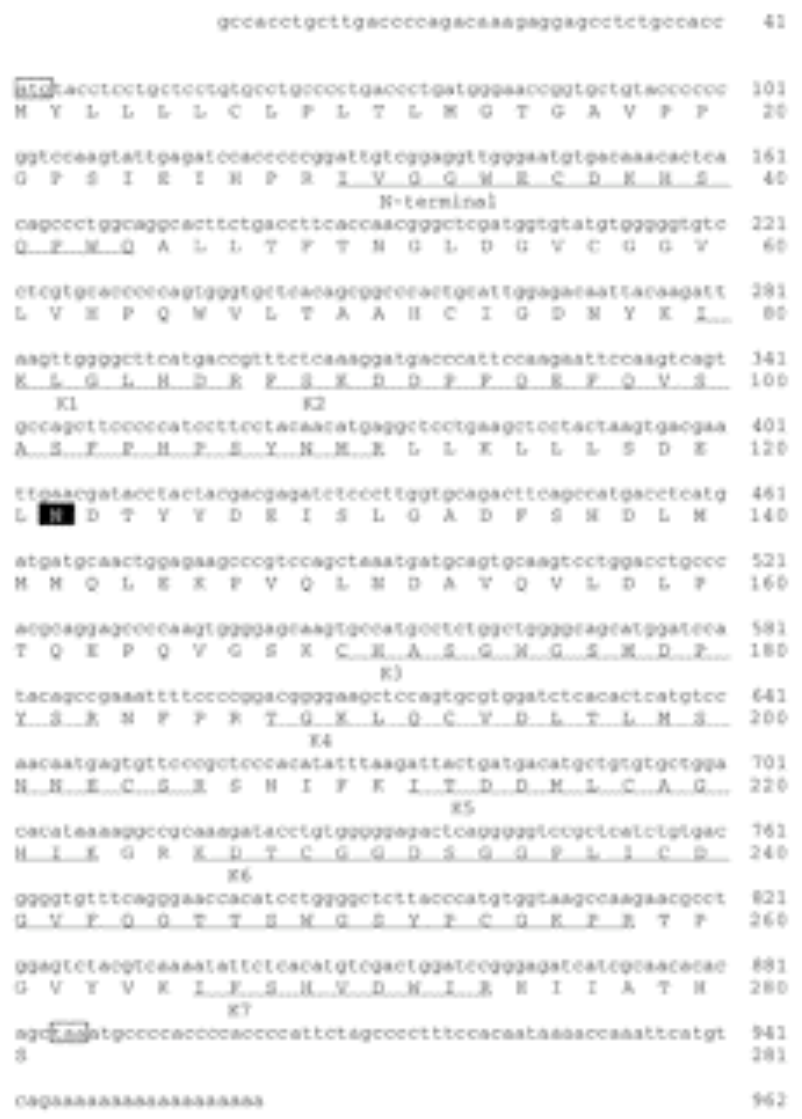

Figure 2 Nucleotide Sequence of cDNA and Deduced Amino Acid Sequence of Blarinasin.

Analysed amino acid sequences of the $\mathrm{N}$-terminal 15 residues of the purified blarinasin and the tryptic peptides (K1-K7) are underlined. The translation-initiation site (ATG) and stop codon (TAA) are boxed. The putative $\mathrm{N}$-glycosylation site in the blarinasin sequence is highlighted in black. Isolation of the total RNA from the submaxillary and sublingual glands of $B$. brevicauda, preparation of first-strand cDNA template, and RT-PCR using degenerate oligonucleotides designed from conserved amino acid sequences within the active sites of mammal kallikreins were carried out as described previously (Kita et al., 2004). The 22 independent clones were sequenced, 7 matched the sequences corresponding to the amino acid sequences within blarinasin. BLTX and 
one minor tissue kallikrein isoform were obtained from the other clones. Two cycles of 3'-rapid amplification of cDNA ends (RACE) were carried out. A reaction mixture for first cycle contained two primers KLK-gene1 and Oligo-dT, and used the blarinasin cDNAs described above as templates. The reaction mixture for second cycle contained the two primers KLK-gene2 and Oligo-dT and the PCR products of the first reaction. Nucleotide sequences of KLK-gene1 and KLK-gene2, the gene specific primers of blarinasin, and Oligo-dT are 5'- GGCAGCATGAATCCATACAGC $\quad$-3', 5'ATGAGTGTTCCCGCTCCCAC -3', and 5'- CGCAGGAATTTTTTTTTTTTTTT -3', respectively. For the 5'-RACE reaction, PCR was performed using a universal primer mix (long; 5'-CTAATACGACTCACTATAGGGCAAGCAGTGGTATCAACGCAGAGT-3', short; 5'-CTAATACGACTCACTATAGGGC -3'), and the gene specific primer, KLK-gene3, whose sequence is 5'- GATCTCGTCGTAGTAGGTATCGTTCA -3'. The full-length blarinasin cDNA was confirmed by PCR, using KLK-gene4 and KLK-gene5. Nucleotide sequences of KLK-gene4 and KLK-gene5, are 5'GCCACCATGTACCTCCTGCTCCT -3' and 5'- GCATTTAGCTGTGTGTTGCGAT -3', respectively. The PCR conditions were as follows: an initial denaturing at $94^{\circ} \mathrm{C}$ for $3 \mathrm{~min}$, followed by 30 cycles of $30 \mathrm{sec}$ of denaturing at $94^{\circ} \mathrm{C}, 30 \mathrm{sec}$ of annealing at $60^{\circ} \mathrm{C}$, and $60 \mathrm{sec}$ of extension at $72^{\circ} \mathrm{C}$, and a final extension at $72^{\circ} \mathrm{C}$ for $7 \mathrm{~min}$. The amplified DNA fragments were subcloned and 7 independent clones were sequenced. All clones revealed an identical sequence. 

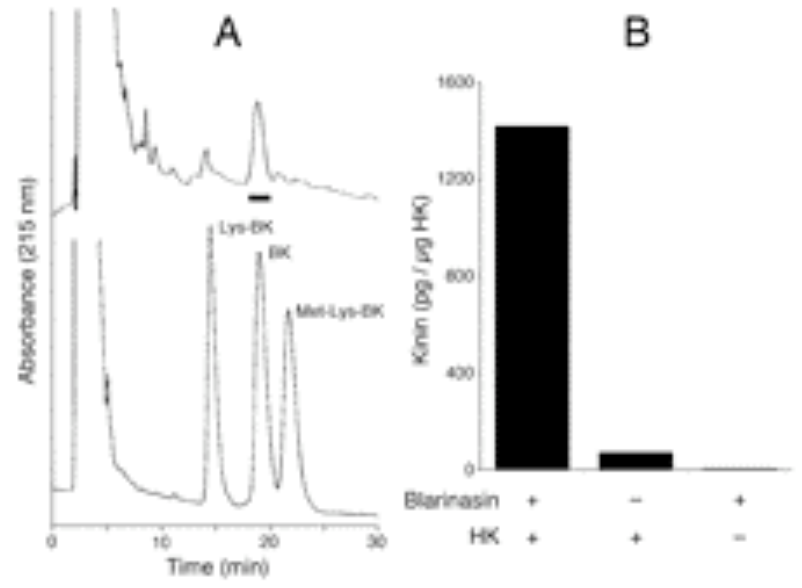

Figure 3 Kinin-releasing Activity of Blarinasin.

$\mathrm{HK}$ at a dose of $10 \mu \mathrm{g}$ was incubated with $400 \mathrm{ng}$ of blarinasin in $50 \mathrm{~mm}$ Tris $\cdot \mathrm{HCl}, \mathrm{pH} 8.5$, at $37^{\circ} \mathrm{C}$ for $1 \mathrm{~h}$ as previously described (Kita et al., 2004). (A) After incubation, products in the reaction mixture were separated by HPLC. The upper and lower traces show the peptides released from $\mathrm{HK}$ after incubation with blarinasin and standard kinins (50 ng each), respectively. The solid bar shows BK. (B) Kinin concentrations in the reaction mixtures were determined with a competitive enzyme-linked immunosorbent assay (ELISA) using a Markit-M bradykinin kit (Dainippon Pharmaceutical Co., Ltd., Osaka, Japan). 

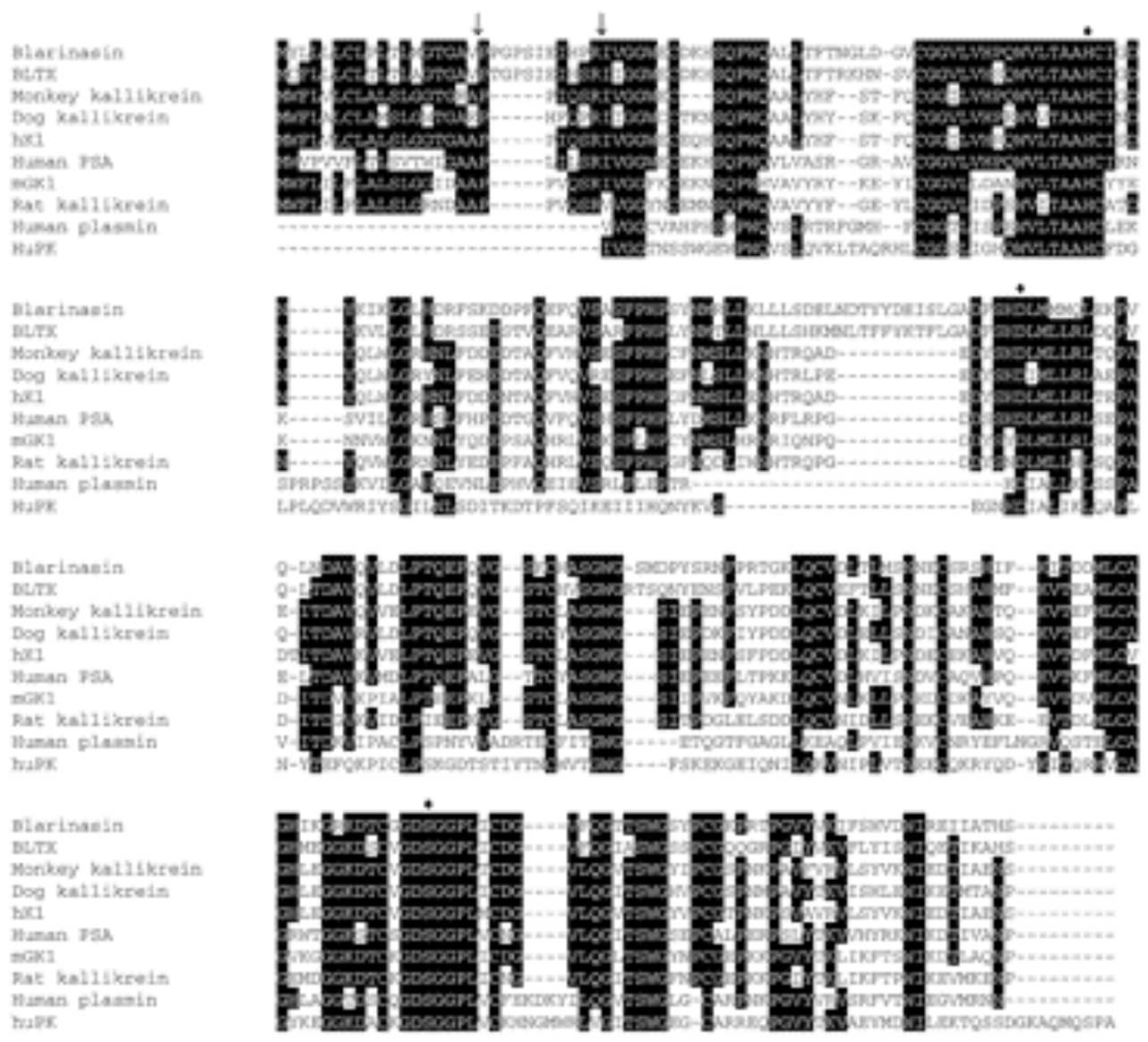

Figure 4 Structure-based Sequence Alignment of Active Forms of Blarinasin, BLTX, and Several Proteases Contained in Tissue Kallikrein Family.

Putative catalytic site residues are marked with a diamond $(\bullet)$. Arrow shows putative processing sites of pro- and mature forms of blarinasin, BLTX, and various kallikreins. Amino acid sequences that are identical in $>5$ of the 10 sequences are highlighted in black. $\mathrm{BLTX}=$ blarina toxin; Monkey kallikrein = glandular kallikrein 1 from the crab-eating macaque Macaca fascicularis; Dog kallikrein = pancreas kallikrein from Canis familiaris; hK1 = human tissue kallikrein 1; Human PSA = human prostate specific antigen (tissue kallikrein 3); mGK1 = mouse tissue kallikrein 1; RUK1 = rat urinary kallikrein 1 ; huPK = human plasma kallikrein. 